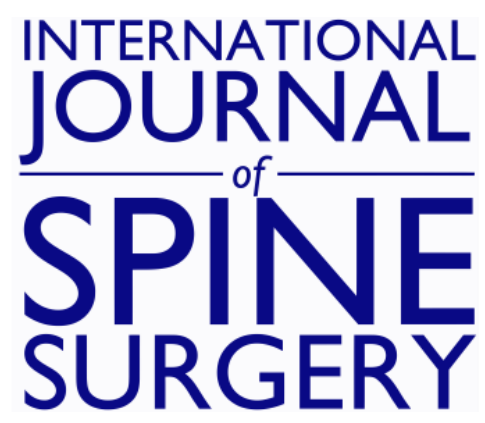

\title{
Chronic Low Back Pain Occurring in Association With Hypermobility Spectrum Disorder and Ehlers-Danlos Syndrome
}

Kelechi C. Eseonu, Kathy Payne, Stephen Ward, Bahram Fakouri and Jaykar R. Panchmatia

Int J Spine Surg 2021, 15 (3) 449-457

doi: https://doi.org/10.14444/8067

http://ijssurgery.com/content/15/3/449

This information is current as of April 26, 2023.

Email Alerts Receive free email-alerts when new articles cite this article. Sign up at: http://ijssurgery.com/alerts 


\title{
Chronic Low Back Pain Occurring in Association With Hypermobility Spectrum Disorder and Ehlers-Danlos Syndrome
}

\author{
KELECHI C. ESEONU, BSC, MSC, MB CHB, FRCS, KATHY PAYNE, BSC, MCSP, GRAD DIP AP, MMACP, \\ STEPHEN WARD, MBBS, FRCA, FFPMRCA, BAHRAM FAKOURI, MD, FRCS, \\ JAYKAR R. PANCHMATIA, MA, MPH, MB BCHIR, FRCS \\ Guy's and St Thomas' Hospitals, London, England
}

\begin{abstract}
Background: This review paper outlines recent advances in diagnostic criteria for hypermobility spectrum disorder (HSD) and its association with Ehlers-Danlos syndrome (EDS), as well as current literature on the association between joint hypermobility syndrome and lumbar back pain. We outline the optimal multidisciplinary management of lumbar back pain in the context of joint hypermobility syndrome, as well as the indications and possible side effects of surgical management of patients with these conditions.

Several studies have suggested a link between chronic low back pain and hypermobility. HSD has been described as an excessive range of motion in a joint, when accounting for patient demographics. The nomenclature surrounding symptomatic joint hypermobility has varied historically, and various groups, including most notably the international EDS consortium, have introduced new classification schemes to acknowledge the systemic effects of joint hypermobility, which were previously poorly understood.

Methods: Narrative literature review.

Results: Not applicable.

Conclusions: Lower back pain experienced in patients on the HSD-EDS spectrum is multifactorial in origin and should not be considered solely in anatomical terms. Caution has been advised in the surgical management of patients on the HSD-hEDS spectrum, particularly where the subtype is unclear. The vascular type of EDS has a particular propensity for severe bleeding complications. Rates of perioperative complications after lumbar spinal surgery in the hypermobile EDS population have been reported to be up to $50 \%$. When hypermobility and chronic lumbar back pain coexist, we advocate management in a multidisciplinary setting involving physiotherapists, pain physicians, surgeons, and psychologists.

Lumbar Spine

Keywords: joint hypermobility syndrome, Ehlers-Danlos syndrome, lumbar back pain, joint hyperlaxity
\end{abstract}

\section{BACKGROUND}

Joint hypermobility $(\mathrm{JH})$ has been described as an "excessive range of motion in a joint, when accounting for patient demographics including age, gender and ethnicity." $1 \mathrm{JH}$ may be present in an isolated joint or can be a feature of a widespread connective tissue disorder with generalized joint hypermobility and nonarticular manifestations. ${ }^{2,3}$

The nomenclature surrounding symptomatic JH has varied historically. The diagnostic term joint hypermobility syndrome (JHS) was initially used when patients experienced symptoms associated with multijoint laxity. As our understanding of JHS evolved, there was a belief that the condition was often indistinguishable from hypermobile Ehlers-Danlos (hEDS), and as such the 2 terms were often used interchangeably. ${ }^{4,5}$ In 2017 , the International EDS Consortium proposed a revised EDS classification, which recognized 13 subtypes, clarified the diagnosis of hEDS, and discontinued use of the term JHS (Table 1; Figure 1). This consortium introduced the term hypermobility spectrum disorder (HSD), which was used to encompass those patients with symptoms associated with their hypermobility but not fulfilling the criteria of hEDS or any other heritable disorder of connective tissue (HDCT; Figure 2). ${ }^{5}$

It is estimated that $3.4 \%$ of the population have generalized joint hypermobility and associated 
Table 1. Updated EDS Classification (Ehlers-Danlos Society). The new subtype is in bold.

\begin{tabular}{|c|c|c|c|}
\hline EDS Subtype & Inheritance Pattern & Gene & Protein \\
\hline Classic & $\mathrm{AD}$ & Major: $C O L 5 A 1 / C O L 5 A 2$ & Procollagen type V \\
\hline Classical-like EDS & & Rare: $C O L 1 A 1$ & $\begin{array}{l}\text { Procollagen type I } \\
\text { Tenascin-X }\end{array}$ \\
\hline $\begin{array}{l}\text { Classical-11ke EDS } \\
\text { Cardiac-valvular }\end{array}$ & $\begin{array}{l}\text { AR } \\
\text { AR }\end{array}$ & $\begin{array}{l}\text { INX-B } \\
\text { COL1A2 }\end{array}$ & $\begin{array}{l}\text { Deficiency of } \alpha 2(I) \text { collagen } \\
\text { chain }\end{array}$ \\
\hline Hypermobility & AD & Unknown & Unknown \\
\hline Vascular & $\mathrm{AD}$ & $\begin{array}{l}\text { Major: COL3A1 } \\
\text { Rare: COL1A1 }\end{array}$ & $\begin{array}{l}\text { Type III collagen } \\
\text { Type I collagen }\end{array}$ \\
\hline Arthrochalasia & $\mathrm{AD}$ & COL1A1, COL1A2 & Type I collagen \\
\hline Dermatosparaxis & $\mathrm{AR}$ & ADAMTS2 & ADAMTS-2 \\
\hline Kyphoscoliotic EDS & AR & $\begin{array}{l}\text { PLOD1 } \\
\text { FKBP14 }\end{array}$ & $\begin{array}{l}\text { LH1 } \\
\text { FKBP22 }\end{array}$ \\
\hline Brittle cornea syndrome & AR & $\begin{array}{l}\text { ZNF469 } \\
\text { PRDM5 }\end{array}$ & $\begin{array}{l}\text { ZNF469 } \\
\text { PRDM5 }\end{array}$ \\
\hline Spondylodysplastic & AR & $\begin{array}{l}\text { B4GALT7 } \\
\text { B3GALT6 } \\
\text { SLC39A13 }\end{array}$ & $\begin{array}{l}\text { B3GalT7 } \\
\text { B3GalT6 } \\
\text { ZIP13 }\end{array}$ \\
\hline Musculocontractual & AR & $\begin{array}{l}\text { CHST14 } \\
\text { DSE }\end{array}$ & $\begin{array}{l}\text { D4ST1 } \\
D S E\end{array}$ \\
\hline Myopathic & $\mathrm{AD}$ or $\mathrm{AR}$ & COL12A1 & Type XII collagen \\
\hline Periodontal & AD & $\mathrm{C} 1 \mathrm{R}$ & Clr \\
\hline
\end{tabular}

Abbreviations: AD, autosomal dominant; AR, autosomal recessive; EDS, Ehlers-Danlos syndrome.

chronic widespread pain., ${ }^{4,5}$ This prevalence rivals fibromyalgia, gout, and rheumatoid arthritis. ${ }^{6}$ Despite its prevalence, it is underdiagnosed by physicians due to its highly variable clinical presentation and controversies regarding its etiology, nomenclature, and pathogenesis. ${ }^{7,8}$

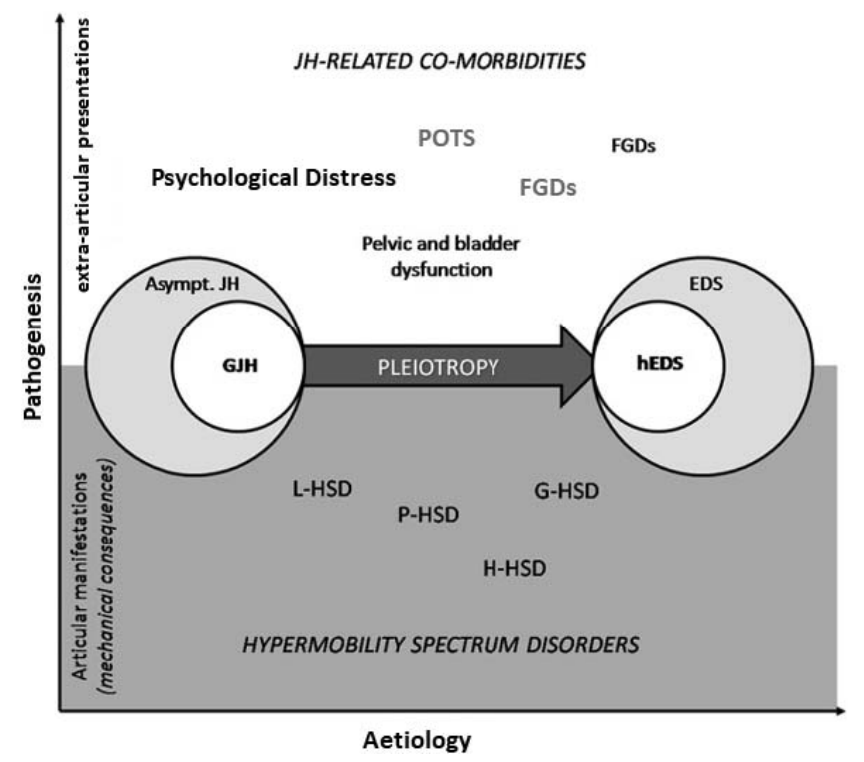

Figure 1. Two-dimensional variability of joint hypermobility syndrome represented by the vertical (pathogenesis) and horizontal (etiology). Centrally, the relationships between the domains of asymptomatic joint hypermobility and Ehlers-Danlos syndrome. Generalized joint hypermobility and hypermobile Ehlers-Danlos syndrome are highlighted as the closest phenotypes, within the corresponding domains. Abbreviations: EDS, Ehlers-Danlos syndrome (various types); FGDs, functional gastrointestinal disorders; G-HSD, generalized hypermobility spectrum disorder; GJH, generalized joint hypermobility; hEDS, hypermobile Ehlers-Danlos syndrome; JH, joint hypermobility (various types); $\mathrm{H}$ HSD, historical hypermobility spectrum disorder; L-HSD, localized hypermobility spectrum disorder; P-HSD, peripheral hypermobility spectrum disorder; POTS, postural orthostatic tachycardia syndrome.
Several studies have suggested a link between chronic low back pain (cLBP) and hypermobility. ${ }^{9,10}$ Given the current understanding of the existence of HSD and hEDS on a continuum, we have referenced articles using both terms, as well as the historical term JHS. The aims of this article are to outline a new classification system for these connective tissue disorders (HSD and hEDS); to discuss the identification of these patients in clinic; and finally, to offer some guidance on the management of cLBP in patients with hEDS.

\section{DIAGNOSIS AND SEQUELAE OF HYPERMOBILITY SYNDROMES}

The diagnosis of both HSD and hEDS are diagnoses of exclusion. Patients will often give a history of subluxations and dislocations coexisting with dermatological symptoms such as extensive bruising. These are often associated with abnormal pain processing, fatigue, autonomic dysfunction, mental health symptoms, and wider visceral involvement such as uterine prolapse and abdominal hernias. ${ }^{4,5}$ Patients may also have a positive family history of hypermobility, but the spectrum of system involvement and severity of presentation varies widely.

Given that the history may be vague, a detailed musculoskeletal examination is key. The measurement of joint hypermobility can be supported by a number of scoring systems, the most prevalent of which is the Beighton score (Table 2). ${ }^{11}$ First 


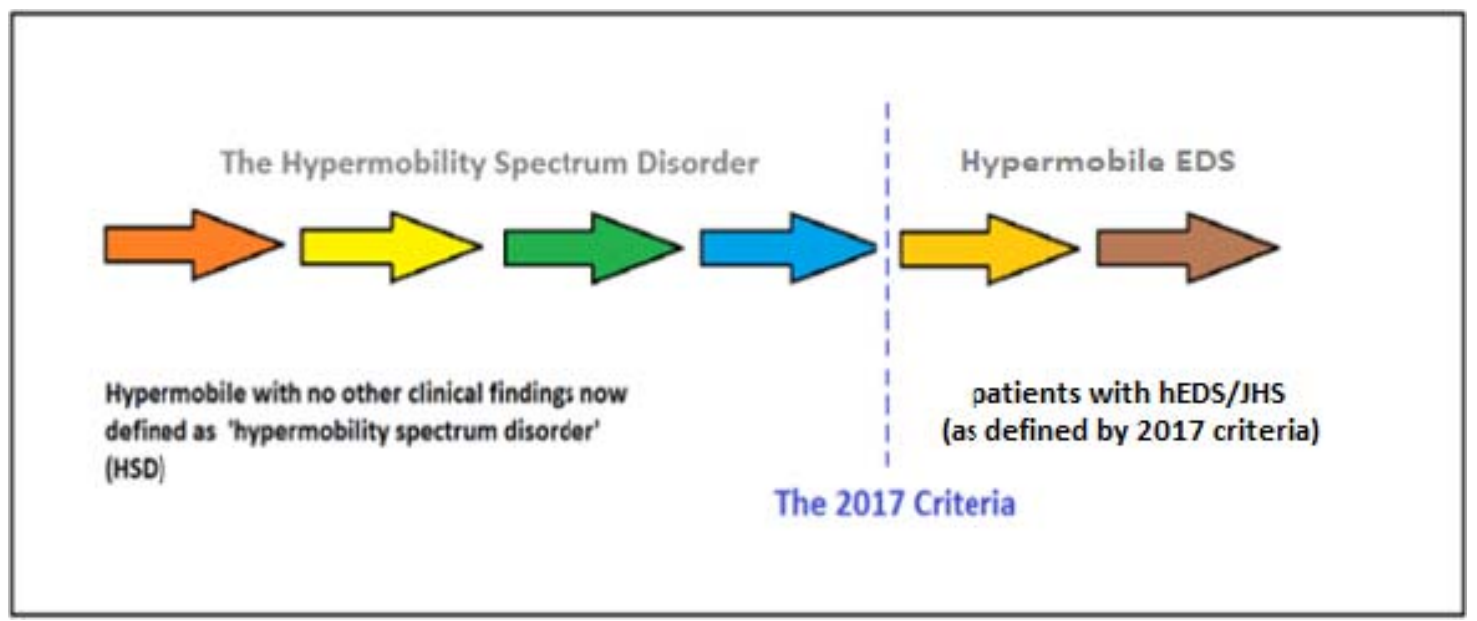

Figure 2. The Hypermobility Syndromes Association (HMSA)/International Consortium with the Ehlers-Danlos Society Diagnostic Criteria (2017) representing the spectrum of presentations between hypermobility spectrum disorder and JHS/EDS hypermobility type. Abbreviations: EDS, Ehlers-Danlos syndrome; EJHS, joint hypermobility syndrome; HMSA, Hypermobility Syndromes Association.

described in 1976, it is based on the results of 9 joint examinations of only 5 areas. In the case of each examination, a positive sign is scored 1 point, with 0 points for a negative sign. The scores for all examinations are added together, with the highest possible score being 9. The threshold indicative of generalized increased joint laxity was related to age, with $6-7$ in adolescents and $\geq 4$ in those over 50 years of age, ${ }^{12}$ although other cutoff values have also been applied. ${ }^{13,14}$

Primarily devised for epidemiological use, as opposed to a diagnostic tool, the Beighton score provides an indication of joint laxity as part of wider syndromic assessment. ${ }^{15}$ It fails to account for the degree of joint laxity because it measures each joint in binary terms, covers only 5 areas, and does not consider rotation at any joint. However, these limitations make it clinically pragmatic. It is well validated and has been shown to have high interobserver and intraobserver reliability. ${ }^{16} \mathrm{~A}$ dermatological, cardiovascular, and abdominal examination also needs to be performed.

Table 2. Beighton 9-point scoring system.

\begin{tabular}{lccc}
\hline & \multicolumn{2}{c}{ Points } \\
\cline { 2 - 3 } Maneuver & Right & Left \\
\hline $\begin{array}{l}\text { Ability to passively dorsiflex the } 5 \text { th } \\
\text { metacarpophalangeal joint to } 90^{\circ}\end{array}$ & 1 & 1 \\
$\begin{array}{c}\text { Ability to appose the thumb to the volar aspect of the } \\
\text { ipsilateral forearm }\end{array}$ & 1 & 1 \\
$\begin{array}{l}\text { Ability to hyperextend the elbow joint to beyond } 10^{\circ} \\
\text { Ability to hyperextend the knee joint to beyond } 10^{\circ} \\
\begin{array}{l}\text { Ability to place hands flat on the floor by bending } \\
\text { forward with knees fully extended }\end{array} \\
\quad \text { Total }\end{array}$ & 1 & & 1 \\
\hline
\end{tabular}

On completing a detailed assessment, clinical findings should be referenced against the established set of diagnostic criteria. The new diagnosis of HSD includes most patients who were previously diagnosed with JHS or benign joint hypermobility syndrome (BJHS) and some who were previously diagnosed with hEDS. It includes all patients with hypermobility who do not fulfill the revised hEDS criteria.

For a patient to be diagnosed with hEDS, 3 specific criteria need to be fulfilled (Tables 3-5). This classification system accounts for the fact that the diagnosis of hEDS should include not only joint examination and calculation of joint hypermobility using the Beighton score, but also other clinical signs such as a Marfanoid habitus and aspects of tissue laxity, including weakness of supporting structures such as the abdominal wall (hernia) and pelvic floor (genito-uterine prolapse).

Table 3. 2017 Ehlers-Danlos syndrome classification—criteria 1, generalized joint hypermobility.

Beighton score should be calculated and one of the following selected.

Prepubertal children and adolescents - 6

Pubertal men and women to the age of $50 \mathrm{y}-5$

Men and women over the age of $50 \mathrm{y}$

If Beighton score is equal to or higher than the score allocation (as above), the criteria is fulfilled. If it is 1 point below, then 2 of the following must be present to fulfill criteria 1.

Can you now (or could you ever) place your hands flat on the floor without bending your knees?

Can you now (or could you ever) bend your thumb to touch your forearm?

As a child or teenager, did your shoulder or kneecap dislocate on more than one occasion?

Do you consider yourself "double-jointed"? 
Table 4. 2017 Ehlers-Danlos syndrome classification—criteria 2.

Two or more of the following features $(\mathrm{A}, \mathrm{B}$, or $\mathrm{C})$ must be present for criteria 2 to be fulfilled.

Feature A ( 5 must be present for feature A to be fulfilled)

Unusually soft or velvety skin

Mild skin hyperextensibility

Unexplained striae distensae or rubae at the back, groins, thighs, breasts, and/or abdomen in adolescents, men, or prepubertal women without a history of significant gain or loss of body fat or weight

Bilateral piezogenic papules of the heel

Recurrent or multiple abdominal hernia(s)

Atrophic scarring involving at least 2 sites and without the formation of truly papyraceous and/or hemosideric scars as seen in classical EDS

Pelvic floor, rectal, and/or uterine prolapse in children, men, or nulliparous women without a history of morbid obesity or other known predisposing medical condition

Dental crowding and high or narrow palate

Arachnodactyly, as defined in 1 or more of the following: (1) positive wrist sign (Walker sign) on both sides, (2) positive thumb sign (Steinberg sign) on both sides

Arm span to height ratio $\geq 1.05$

Mitral valve prolapse mild or greater on the basis of strict echocardiographic criteria

Aortic root dilatation with $z$ score $>2$

Feature B

Positive family history: 1 or more first-degree relatives independently meeting the current criteria for hEDS

Feature C (must have at least 1 )

Musculoskeletal pain in 2 or more limbs, recurring daily for at least 3 months

Chronic, widespread pain for $\geq 3$ months

Recurrent joint dislocations or frank joint instability, in the absence of trauma

Abbreviation: hEDS, hypermobile Ehlers-Danlos syndrome.

\section{ASSOCIATION BETWEEN HYPERMOBILITY AND CHRONIC BACK PAIN}

The presentation of cLBP in a patient on the HSD-hEDS spectrum is often unrelated to underlying structural issues, so a multifaceted approach to their clinical management is needed. ${ }^{17}$

The seminal early work on hypermobility and back pain was published in a Swedish study ${ }^{18}$ in 1995, which analyzed 606 industrial workers who were examined for these conditions (Table 6). Larsson et $\mathrm{al}^{18}$ hypothesized that hypermobility of a joint was "an asset if the joint was involved in repetitive motion and a liability if the primary role of the joint was supportive." They identified an association between hypermobility and increased incidence of back pain and found a stronger correlation in women than men. It was speculated that this could be due to the protective effect of muscle mass in male patients. ${ }^{18}$

The study concluded that the paravertebral muscles in subjects with JHS (as defined in their
Table 5. 2017 Ehlers-Danlos syndrome classification-criteria 3.

All of the following prerequisites MUST be met

1: Absence of unusual skin fragility, which should prompt consideration of other types of EDS

2: Exclusion of other heritable and acquired connective tissue disorders, including autoimmune rheumatologic conditions. In patients with an acquired connective tissue disorder (CTD) (eg, lupus, rheumatoid arthritis), additional diagnosis of hEDS requires meeting both features $\mathrm{A}$ and $\mathrm{B}$ of criterion 2. Feature $\mathrm{C}$ of criterion 2 (chronic pain and/or instability) cannot be counted toward a diagnosis of hEDS in this situation

3: Exclusion of alternative diagnoses that may also include joint hypermobility by means of hypotonia and/or connective tissue laxity. Alternative diagnoses and diagnostic categories include, but are not limited to, neuromuscular disorders (eg, Bethlem myopathy), other hereditary disorders of the connective tissue (eg, other types of EDS, Loeys-Dietz syndrome, Marfan syndrome), and skeletal dysplasias (eg, osteogenesis imperfecta). Exclusion of these considerations may be based upon history, physical examination, and/or molecular genetic testing, as indicated.

Abbreviations: CTD, connective tissue disease; EDS, Ehlers-Danlos syndrome; hEDS, hypermobile Ehlers-Danlos syndrome.

work) had to bear more load to compensate for ligamentous laxity to maintain support of their own body weight and facilitate physical activity. The increase in exertion required of the paraspinous musculature was believed to cause back pain, leading to higher disability and higher visual analog scale (VAS) scores for back pain. Another explanation for this association was that excessive joint laxity could lead to mechanical overload on intervertebral disc and facet joints, accelerating changes that may result in worsening back pain.

The Johnston County project specifically aimed to assess differences in the association between JHS and lumbar spinal symptoms stratified by race. ${ }^{14}$ The study sampled 1864 white and African American patients aged 56-76 years. A positive association between JHS (as measured by Beighton score) and back pain was identified among white patients (adjusted odds ratio $[\mathrm{aOR}])=1.54 ; 95 \% \mathrm{CI}, 1.00$ 2.39), but a nonsignificant inverse relationship between Beighton score and back pain was identified among African-Americans $(\mathrm{OR}=0.77 ; 95 \% \mathrm{CI}$, 0.34-1.72). Authors did not offer a definitive explanation for this marked difference between racial groups in the association between JHS and back pain.

Various studies have assessed the significance of lumbar spinal segmental hypermobility on back pain. Kim et $\mathrm{al}^{10}$ performed a retrospective casecontrol analysis, sampling 32 young male patients with a Beighton score $\geq 4$ (JHS group), age, race, 
Table 6. Published studies investigating the association between back pain/lumbar degeneration and hypermobility.

\begin{tabular}{|c|c|c|c|}
\hline Article Title (Author, Year) & No. Patients & Variables & Results \\
\hline \multirow{3}{*}{$\begin{array}{l}\text { Goode et al (2019) } \\
\quad \text { *Including GO, GOGO, } \\
\text { and JoCo studies }\end{array}$} & *5072 & $\begin{array}{l}\text { Joint hypermobility (JH) (Beighton score } \\
>4) \& \text { incidence of back pain }\end{array}$ & $\mathrm{pOR}=0.86(95 \% \mathrm{CI}, 0.66-1.07)$ \\
\hline & & $\mathrm{JH} \&$ incidence of lumbar spinal OA & $\mathrm{pOR}=0.92(95 \% \mathrm{CI}, 0.72-1.12)$ \\
\hline & & $\mathrm{JH}$ vs incidence of facet $\mathrm{OA}$ & $\mathrm{pOR}=0.75(0.55-0.94)$ \\
\hline \multirow{2}{*}{ Kim et al $(2013)^{10}$} & 32 & JH \& VAS for back pain & $19.29(\mathrm{JH})$ vs 8.26 (control), $(P<.001)$ \\
\hline & & JH \& ODI & $9.86(\mathrm{JH})$ vs 5.32 (control), $(P<.006)$ \\
\hline Kim et al $(2013)^{10}$ & 101 & $\begin{array}{l}\text { JH \& incidence of lumbar disc } \\
\text { degeneration }\end{array}$ & $26.5 \%(\mathrm{JH})$ vs $53.7 \%$ (control) $(P=.009)$ \\
\hline Dolan et al $(2003)^{3}$ & 716 & JH \& incidence of back pain & $62 \%(\mathrm{JH})$ vs $64 \%$ (control) $(P=.45)$ \\
\hline Tobias et al $(2013)^{9}$ & 2901 & JH \& Lumbar back pain & $\mathrm{pOR}=1.30(0.85-2.00) P=.229$ \\
\hline \multirow[t]{2}{*}{ Biering-Sørensen (1983) } & 920 & $\begin{array}{l}\text { Spinal flexibility (Schober test) vs } \\
\text { incidence of lower back pain }\end{array}$ & $\begin{array}{l}\text { Men: Patients with back pain had mean } \\
\text { distance of } 71.9 \mathrm{~mm} \text { of flexibility on } \\
\text { Schober test vs } 67.2 \mathrm{~mm} \text { in patients } \\
\text { without LBP }(P=.012)\end{array}$ \\
\hline & & & $\begin{array}{l}\text { Women: Patients with back pain had mean } \\
\text { distance of } 62.5 \mathrm{~mm} \text { of flexibility on } \\
\text { Schober test vs } 65.3 \mathrm{~mm} \text { in patients } \\
\text { without LBP }(P=.15)\end{array}$ \\
\hline \multirow[t]{3}{*}{ Larsson et al $(1995)^{18}$} & 606 & $\begin{array}{l}\text { JH \& incidence of back pain (sitting and } \\
\text { standing jobs) }\end{array}$ & $40 \%(\mathrm{JH})$ vs $12 \%$ (control),$P<.001$ \\
\hline & & $\begin{array}{l}\text { JH \& incidence of back pain (jobs with } \\
\text { changing body postures) }\end{array}$ & $4.5 \%(\mathrm{JH})$ vs $14 \%$ (control), $P=.04$ \\
\hline & & $\mathrm{JH} \&$ incidence of back pain (overall) & $26 \%(\mathrm{JH})$ vs $14 \%$ (control), $P<.002$ \\
\hline
\end{tabular}

Abbreviations: CTD, connective tissue disorder; EDS, Ehlers-Danlos syndrome; GO, yyy; GOGO, zzz; hEDS, hypermobile Ehlers-Danlos syndrome; JH, joint hypermobility; LBP, low back pain; OA, osteoarthritis; ODI, Oswestry Disability Index; pOR, prevalence odds ratio; VAS, visual analog scale.

and body mass index matched against 32 young male patients with a Beighton score $<4$ (control group). This study concluded that young men with joint hypermobility had excessive lumbar segmental motion that was associated with increased LBP, disability, and limited physical activity. One study ${ }^{19}$ that provided an interesting opposing view on the association between JHS and LBP was published in 2019. Goode et $\mathrm{al}^{19}$ showed a relationship between the ability to complete a trunk flexion maneuver and the lower incidence of back pain, suggesting a possible protective effect of ligamentous laxity and hypermobility in some cases.

Kim et $\mathrm{al}^{20}$ investigated the association between JHS and lumbar disc degeneration in an MRIbased prospective cross-sectional study of 101 patients between 30 and 40 years old: 34 with joint laxity (as measured by Beighton score) and 67 without joint laxity. Both groups were matched by age and body mass index. Patients with joint laxity showed increased lumbar lordosis $(P=.004)$ and increased sacral slope $(P=.003)$ compared with the control group, without a significant difference in pelvic incidence $(P=.084)$. On univariate analysis, a Beighton score $\geq 4$ was significantly associated with a decreased risk of lumbar disc degeneration.

When managing patients with cLBP and hypermobility (both HSD and hEDS), the treating clinician must be aware that patients may have significant pain in the absence of positive radiological findings. That the experience of LBP is more complex than purely a direct relationship with anatomical radiological changes is well accepted in the literature on cLBP. The evidence of spinal radiological changes in asymptomatic patients that worsen with age is relevant to any interpretation of radiological findings. ${ }^{20}$ This second observation may explain why patients with hypermobility and cLBP may fail to respond to anatomically targeted pain management and surgical intervention.

\section{NEUROPHYSIOLOGIC AND PSYCHIATRIC FEATURES OF HEDS}

There is evidence that hEDS can be associated with central and peripheral nervous system abnormalities, such as autonomic dysfunction. Aktas et $\mathrm{al}^{21}$ have reported a higher incidence of carpal and tarsal tunnel syndrome in these patients. The clinician managing patients with coexisting cLBP and hEDS needs to be cognizant of the risk of peripheral neuropathies, so as not to misdiagnose them as radicular pain that is spinal in origin.

There is evidence of an association between hEDS and anxiety, with a known link between anxiety and intractable chronic pain. ${ }^{22}$ Patients with known hEDS have reported high scores for 


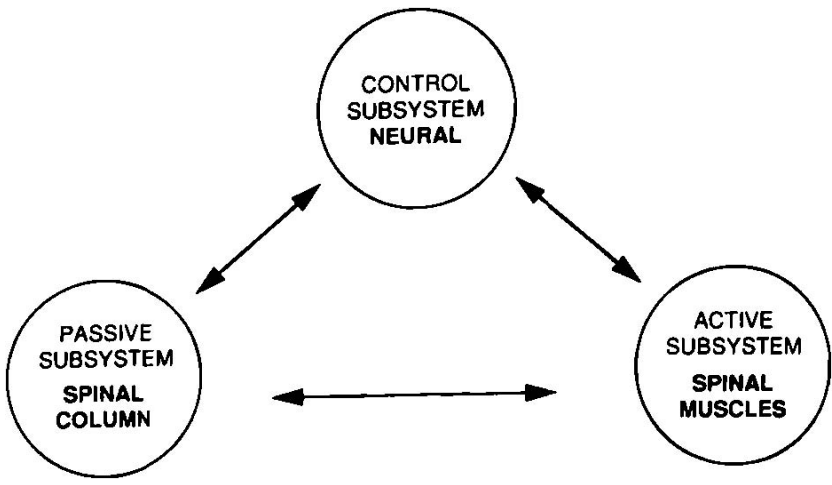

Figure 3. Panjabi spinal stability system representing the 3 spinal subsystems.

fear of movement, as well as pain sensitization. Patients with hypermobility in Norway had higher reported health complaints and a lower understanding of their condition when compared with a control group in a limited qualitative study. ${ }^{23}$ Clinicians should be aware that high back pain scores in some hEDS patients can be secondary to increased perception and/or reduced tolerance of pain or psychosocial factors rather than anatomical pathology.

By being mindful of the neurophysiological and psychiatric features of hEDS, the treating physician can minimize the risk of inappropriately administering targeted spinal interventions.

\section{SPINAL BIOMECHANICS, HYPERMOBILITY, AND BACK PAIN}

Panjabi and White ${ }^{24}$ defined spinal instability as a

loss of the ability of the spine under physiological load to maintain relationships between the vertebrae in such a way that there is neither damage, nor irritation to the spinal cord or nerve roots, or development of incapacitating deformity or pain due to structural changes [see Figure 3].

Spinal stability is the result of 3 subsystems working in harmony: (1) The passive subsystem, consisting of the vertebrae, disc, and ligaments, which resists abnormal spinal motion at extremes of movement; (2) the active subsystem comprising the spinal muscles and tendons, which generate stabilizing forces; and (3) the neural subsystem, made up of the peripheral nerves and central nervous system that coordinate the entire stabilizing system. ${ }^{25}$
In patients with $\mathrm{HSD} / \mathrm{hEDS}$, LBP could be due to a deleterious effect on the normal function of all 3 of these spinal stabilizing subsystems. This relates to the association of hEDS with abnormalities in the collagen framework of connective tissues. ${ }^{26,27}$ The effect this may have on proprioceptive acuity and the challenge of exercise-based management of these patients is an important consideration in rehabilitation.

This abnormality in connective tissue structure could impair the normal function of intervertebral discs and spinous ligaments (passive subsystem) and muscle and tendon function (active subsystem). The association of chronic back pain, both with and without hypermobility, with the neural subsystem through nervous system dysregulation and central sensitization has been established. ${ }^{28,29}$

\section{Nonoperative Management of Back Pain in Hypermobility}

Given the complexity of the HSD-hEDS spectrum and the multifactorial pathogenesis of LBP, a multidisciplinary team approach involving pain specialists, psychologists, surgeons, and physiotherapists is essential. Coordination with a clinical geneticist may facilitate genetic counseling and subtyping if the patient displays severe systemic manifestations or evidence of marfanoid features.

Current physiotherapy techniques aim to regain function and promote self-management. This is achieved by using paced strength and conditioning programs that address proprioceptive challenges and encompass an awareness and management of muscular fatigue. Programs aim to have a strong educational component, to support acute manifestations, such as dislocations and subluxations, and to promote understanding of persistent pain. ${ }^{30}$ Beliefs that may limit exercise participation have been recently explored, resulting in the incorporation of psychological therapies. Back pain scores have been shown to be improved most successfully by rehabilitation programs involving physical and psychological components, compared with exercise alone. $^{31}$

Recommendations based on the efficacy of pain medications for use in the treatment of hypermobility are limited by lack of evidence. ${ }^{32}$ An international consortium has published recent literature on commonly used medication strategies. Paracetamol (acetaminophen, N-acetyl-paminophenol) and nonsteroidal anti-inflammato- 
ry medications (NSAIDS) have been suggested for mild to moderate pain. ${ }^{33,34}$ However, the use of NSAIDS is limited due to poor tolerance secondary to comorbid gastrointestinal issues in hEDS patients. Opioids may be used for a short duration; however, there is good evidence that long-term treatment with opiates is not a viable option and may lead to central pain sensitization. Alternatives such as tricyclic antidepressants, anticonvulsants, serotonin and norepinephrine reuptake inhibitors, and other antidepressants may be used with caution, given the increased risk of dysautonomia in EDS. ${ }^{35,36}$ Pain management in these patients should involve pain specialists at an early stage.

\section{Surgical and Pain Intervention Considerations}

Caution has been advised in the surgical management of patients on the HSD-hEDS spectrum, particularly where the subtype is unclear. Rates of perioperative complications after lumbar spinal surgery in the hEDS population have been reported to be up to $50 \%$. These include slow or incomplete wound healing, increased intraoperative blood loss, and surgical time. ${ }^{37,38}$ The vascular type of EDS has a particular propensity for severe bleeding complications. During the consent process, patients with hypermobility should be counseled regarding the increased risk of poor scar appearance, delayed wound healing, and prolonged rehabilitation. ${ }^{39-41}$

Preoperatively and postoperatively, extreme care should be taken when transferring and positioning these patients, due to the risk of soft tissue abrasions and iatrogenic lacerations. It has been suggested that during an operation, soft tissue retraction should be kept to a minimum and that a multilayered approach ought to be adopted when closing the patient's incision. This reduces the risk of soft tissue injury and hematoma formation while increasing the likelihood of a cosmetically pleasing scar. ${ }^{1}$

Postoperatively, hematology input is essential due to the increased risk of postoperative bleeding and to facilitate appropriate venous thromboembolism prophylaxis, particularly in cases of EDS in which the subtype classification is unclear. Rehabilitation may be more prolonged due to intraoperative bleeding, wound healing, and pain. Fatigue, proprioceptive deficits, coordination, and beliefs about exercise can challenge exercise regimes, prolonging recovery. ${ }^{42}$

\section{CONCLUSIONS}

Patients with hypermobility may present to the clinic with LBP as one manifestation of their condition. Consequently, clinicians treating cLBP need to be confident in identifying both HSD and hEDS and delineating the underlying pathology.

Lower back pain experienced in patients on the HSD-hEDS spectrum is multifactorial in origin and should not be considered solely in anatomical terms. The pain experience in such patients will have multiple influences including those related to fatigue and loss of proprioceptive and postural control and pain processing.

When hypermobility and cLBP coexist, we advocate management in a multidisciplinary setting involving physiotherapists, pain physicians, surgeons, and psychologists. This reflects the fact that these patients are not only at risk of cLBP but also psychological and neurological conditions such as anxiety and peripheral neuropathies. In those cases where spinal surgery is indicated, the patient must be counseled about the increased risk of perioperative complications, prolonged rehabilitation, and recovery.

\section{REFERENCES}

1. Grahame R. Joint hypermobility syndrome pain. Curr Pain Headache Rep. 2009;13(6):427-433. doi:10.1007/s11916009-0070-5

2. Hakim A, Grahame R. Joint hypermobility. Best Pract Res Clin Rheumatol. 2003;17(6):989-1004.

3. Dolan AL, Hart DJ, Doyle DV, et al. The relationship of joint hypermobility, bone mineral density, and osteoarthritis in the general population: the Chingford study. I Rheumatol. 2003;30(4):799-803.

4. Tinkle B, Castori M, Berglund B, et al. Hypermobile Ehlers-Danlos syndrome (aka Ehlers-Danlos syndrome type III and Ehlers-Danlos syndrome hypermobility type): clinical description and natural history. Am J Med Genet C Semin Med Genet. 2017;175(1):48-69. doi:10.1002/ajmg.c.31538

5. Castori M, Tinkle B, Levy H, et al. A framework for the classification of joint hypermobility and related conditions. Am $J$ Med Genet C Semin Med Genet. 2017;175(1):148-157. doi:10. 1002/ajmg.c.31539

6. Mulvey MR, MacFarlane GJ, Beasley M, et al. Modest association of joint hypermobility with disabling and limiting musculoskeletal pain: results from a large-scale general population-based survey. Arthritis Care Res. 2013;65(8):13251333. doi:10.1002/acr.21979

7. Kumar B, Lenert P. Joint hypermobility syndrome: recognizing a commonly overlooked cause of chronic pain. 
Am J Med. 2017;130(6):640-647. doi:10.1016/j.amjmed.2017. 02.013

8. Russek LN, Lashomb EA, Ware AM, et al. United States physical therapists' knowledge about joint hypermobility syndrome compared with fibromyalgia and rheumatoid arthritis. Physiother Res Int. 2016;21(1):22-35. doi:10.1002/ pri. 1613

9. Tobias JH, Deere K, Palmer S, et al. Joint hypermobility is a risk factor for musculoskeletal pain during adolescence: findings of a prospective cohort study. Arthritis Rheum. 2013;65(4):1107-1115. doi:10.1002/art.37836

10. Kim HJ, Yeom JS, Lee DB, et al. Association of benign joint hypermobility with spinal segmental motion and its clinical implication in active young males. Spine (Phila Pa 1976). 2013;38(16):E1013-E1019. doi:10.1097/BRS.0b013e31828ffa15

11. Beighton P, Solomon L, Soskolne CL. Articular mobility in an African population. Ann Rheum Dis. 1973;32(5):413-418. doi:10.1136/ard.32.5.41312

12. Juul-Kristensen B, Schmedling K, Rombaut L, et al. Measurement properties of clinical assessment methods for classifying generalized joint hypermobility - a systematic review. Am J Med Genet C Semin Med Genet. 2017;175(1):116147. doi:10.1002/ajmg.c. 31540

13. Boyle KL, Witt P, Riegger-Krugh C. Intrarater and interrater reliability of the Beighton and Horan joint mobility index. J Athl Train. 2003;38(4):281-285.

14. Chen HC, Shah SH, Li YJ, et al. Inverse association of general joint hypermobility with hand and knee osteoarthritis and serum cartilage oligomeric matrix protein levels. Arthritis Rheum. 2008;58(12):3854-3864. doi:10.1002/art.24319

15. Grahame R, Bird HA, Child A, et al. The revised (Brighton 1998) criteria for the diagnosis of benign joint hypermobility syndrome (BJHS). J Rheumatol. 2000;27(7):1777-1779.

16. Russek LN. Hypermobility syndrome. Phys Ther. 1999;79(6):591-599.

17. Scheper MC, Juul-Kristensen B, Rombaut L, et al. Disability in adolescents and adults diagnosed with hypermobility-related disorders: a meta-analysis. Arch Phys Med Rehabil. 2016;97(12):2174-2187. doi:10.1016/j.apmr.2016.02. 015 .

18. Larsson L-G, Mudholkar GS, Baum J, Srivastava DK. Benefits and liabilities of hypermobility in the back pain disorders of industrial workers. J Intern Med. 1995;238(5):461467

19. Goode AP, Cleveland RJ, Schwartz TA, et al. Relationship of joint hypermobility with low back pain and lumbar spine osteoarthritis. BMC Musculoskelet Disord. 2019;20(1):158. doi:10.1186/s12891-019-2523-2

20. Brinjikji W, Luetmer PH, Comstock B, et al. Systematic literature review of imaging features of spinal degeneration in asymptomatic populations. AJNR Am J Neuroradiol. 2015;36(4):811-816. doi:10.3174/ajnr.A4173

21. Aktas I, Ofluoglu D, Albay T. The relationship between benign joint hypermobility syndrome and carpal tunnel syndrome. Clin Rheumatol. 2008;27(10):1283-1287. doi:10. 1007/s10067-008-0909-x

22. Bulbena A, Baeza-Velasco C, Bulbena-Cabré A, et al. Psychiatric and psychological aspects in the Ehlers-Danlos syndromes. Am J Med Genet C Semin Med Genet. 2017;175(1):237-245
23. Hope L, Juul-Kristensen B, Løvaas H, et al. Subjective health complaints and illness perception amongst adults with joint hypermobility syndrome/ehlers-danlos syndrome-hypermobility type - a cross-sectional study. Disabil Rehabil. 2019;41(3):333-340. doi:10.1080/09638288.2017.1390695

24. Panjabi MM, White AA. Basic biomechanics of the spine. Neurosurgery. 1980;7(1):76-93. doi:10.1227/00006123198007000-00014

25. Panjabi MM. The stabilizing system of the spine: part I. function, dysfunction, adaptation, and enhancement. J Spinal Disord. 1992;5(4):383-389; discussion 397. doi:10.1097/ 00002517-199212000-00001

26. Grahame R. Joint hypermobility and genetic collagen disorders: are they related? Arch Dis Child. 1999;80(2):188-191. doi:10.1136/adc.80.2.188

27. Jesudas R, Chaudhury A, Laukaitis CM. An update on the new classification of Ehlers-Danlos syndrome and review of the causes of bleeding in this population. Haemophilia. 2019;25(4):558-566. doi:10.1111/hae.13800

28. Schabrun SM, Burns E, Thapa T, Hodges P. The response of the primary motor cortex to neuromodulation is altered in chronic low back pain: a preliminary study. Pain Med. 2018;19(6):1227-1236. doi:10.1093/pm/pnx168

29. Ji RR, Nackley A, Huh Y, et al. Neuroinflammation and central sensitization in chronic and widespread pain. Anesthesiology. 2018;129(2):343-366. doi:10.1097/ALN. 0000000000002130

30. Simmonds J V., Herbland A, Hakim A, et al. Exercise beliefs and behaviours of individuals with joint hypermobility syndrome/Ehlers-Danlos syndrome-hypermobility type. Disabil Rehabil. 2019;41(4):445-455. doi:10.1080/09638288.2017. 1398278

31. Efremidou E, Vounotrypidis P, Zezos P, et al. Prevalence of joint hypermobility and patterns of articular manifestations in patients with inflammatory bowel disease. Gastroenterol Res Pract. 2009;2009:924138. doi:10.1155/2009/924138

32. Castori M. Pain in Ehlers-Danlos syndromes: manifestations, therapeutic strategies and future perspectives. Expert Opinion on Orphan Drugs. 2016;4:11:1145-1158. doi:10.1080/ 21678707.2016.1238302

33. Zhou Z, Rewari A, Shanthanna H. Management of chronic pain in Ehlers-Danlos syndrome. Medicine (Baltimore). 2018 Nov;97(45):e13115. doi:10.1097/MD.0000000000013115.

34. Chopra P, Tinkle B, Hamonet C, et al. Pain management in the Ehlers-Danlos syndromes. Am J Med Genet C Semin Med Genet. 2017;175(1):212-219.

35. Scheper MC, De Vries JE, Verbunt J, Engelbert RHH. Chronic pain in hypermobility syndrome and Ehlers-Danlos syndrome (hypermobility type): it is a challenge. J Pain Res. 2015.

36. Di Stefano G, Celletti C, Baron R, et al. Central sensitization as the mechanism underlying pain in joint hypermobility syndrome/Ehlers-Danlos syndrome, hypermobility type. Eur J Pain. 2016;20(8):1319-1325. doi:10.1002/ ejp. 856

37. Uhorchak JM, Scoville CR, Williams GN, et al. Risk factors associated with noncontact injury of the anterior cruciate ligament. A prospective four-year evaluation of 859 West Point cadets. Am J Sports Med. 2003;31(6):831-842. doi: $10.1177 / 03635465030310061801$ 
38. Decoster LC, Bernier JN, Lindsay RH, Vailas JC. Generalized joint hypermobility and its relationship to injury patterns among NCAA lacrosse players. J Athl Train. 1999;34(2):99-105.

39. Rozen TD, Roth JM, Denenberg N. Cervical spine joint hypermobility: a possible predisposing factor for new daily persistent headache. Cephalalgia. 2006;26(10):1182-1185. doi:10.1111/j.1468-2982.2006.01187.x

40. Akpinar S, Gogus A, Talu U, et al. Surgical management of the spinal deformity in Ehlers-Danlos syndrome type VI. Eur Spine J. 2003;12(2):135-140. doi:10.1007/ s00586-002-0507-6

41. Rabenhorst BM, Garg S, Herring JA. Posterior spinal fusion in patients with Ehlers-Danlos syndrome: a report of six cases. J Child Orthop. 2012;6(2):131-136. doi:10.1007/s11832012-0393-3

42. Rombaut L, Malfait F, De Wandele I, et al. Medication, surgery, and physiotherapy among patients with the hypermobility type of ehlers-danlos syndrome. Arch Phys
Med Rehabil. 2011;92(7):1106-1112. doi:10.1016/j.apmr. 2011.01 .016

Disclosures and COI: The authors received no funding for this study and report no conflicts of interest.

Corresponding Author: Mr Kelechi Eseonu, Guys and St Thomas' Hospital, London, SE1 9RT UK. Phone: 07837897720; Email: kelechi.eseonu@ doctors.org.uk.

Published 1 June 2021

This manuscript is generously published free of charge by ISASS, the International Society for the Advancement of Spine Surgery. Copyright (C) 2021 ISASS. To see more or order reprints or permissions, see http://ijssurgery.com. 